\title{
No end to nuclear decay?
}

\section{The stagnation of the nuclear power industry in the United States should be an incentive for radical thinking rather than an excuse for despair.}

THE predicament of the nuclear power industry in the United States will get worse before it gets better. Last July, nuclear power provided the occasion for the biggest municipal default in history, when the Washington Public Power Supply System failed to meet its payments on bonds worth more than $\$ 2,000$ million. More financial embarrassments are in store. It appears to be only a matter of time, for example, before the Long Island Lighting Company (LILCO) concedes that its Shoreham plant, which is already a decade behind schedule and seems likely to cost 15 times more than intended, will never be allowed to operate. LILCO's chief executive, Dr William Catacosinos, admitted for the first time last week that it might be simpler for the utility to abandon Shoreham than to continue its enervating struggle with the local municipality, Suffolk County. Suffolk, it will be remembered, has done its utmost to thwart LILCO's plans for Long Island by refusing to participate in the emergency evacuation planning mandated by the Nuclear Regulatory Commission (NRC).

Shoreham's plight is a depressingly familiar (but exceptionally acute) compound of engineering, economic and political failures, failures that have contributed to the fact that there has not been a single new order for a nuclear reactor in the United States since 1978. The nuclear industry, supported by the Reagan Administration, lays much of the blame at the door of NRC. Less cumbersome procedures, fewer opportunities for public intervention and a limit on the number of design "backfits" ordered by NRC could, it is suggested, transform the economics of reactor construction. But there is little point in looking for relief in that direction. Congress, backed by public opinion (half of the public is opposed to building nuclear plants, a third supports it), is in no mood to reduce the powers of NRC, a body which is criticized for too cosy a relationship with the industry at least as often as it is accused of over-zealous enforcement of its rules. There may indeed be a case for strengthening NRC procedures in order to revive public confidence in the safety of nuclear energy.

It is in any case far from clear that regulatory reform by itself would do much to alter the predicament of the industry. The two main causes of that predicament are the abrupt fall in the rate of growth in electricity demand since 1973 and the simultaneous increase in the costs of nuclear reactor construction. Between 1960 and 1972, electric utilities took for granted annual growth rates of 7 per cent, and it is on those assumptions that existing nuclear power construction was predicted. In practice, growth has averaged only 2.5 per cent a year since 1973 . Moreover, the costs of building nuclear plants doubled in constant dollars during the 1970 s and are expected to increase by another 80 per cent for plants now under construction. Some of this increase can be ascribed to new regulatory requirements but not much, according to a new study, Nuclear Power in an Age of Uncerrtainty, published by the Office of Technology Assessment (OTA) last week. OTA points out that of the group of plants now being built, the most expensive is expected to cost more than four times as much as the least expensive. The variation has something to do with regional labour costs and differences in weather but is primarily a result of differences in the competence and experience of management.

So it is to its own management, rather than to external agencies, that the nuclear industry should look for a way out of the impasse in which it finds itself. Unfortunately, industry managers show little enthusiasm for tackling any of the major structural problems that have to be solved. There is a temptation instead to ride out the hiatus in orders for new plants in the hope that demand for nuclear power will revive when the demand for electricity revives. Meanwhile there is a reasonable living to be made by servicing existing plants and, from time to time, selling reactors overseas.

That strategy might work, if the hoped-for recovery were to come within five years. But if the hiatus lasts a decade or more, the prospects for reviving the industry are much less promising. According to OTA, the lack of orders for new plants is already creating shortages of spare parts and personnel. Enrolment for nuclear engineering degrees has declined since the mid-1970s, and graduate numbers will barely be enough to fill the anticipated need for 6,000 engineers to operate plants by 1991. Instead of alternately sitting on its hands and wringing them, the industry should be acting now to ensure that the hiatus ends sooner rather than later.

What can be done? For a start, the industry could stop talking about standardized designs and actually begin to standardize them. Without some degree of standardization, as in France, construction of nuclear reactors is unlikely to be able to compete with coal-fired plants. Standardization would require ruthless surgery to reduce the proliferation of vendors and designers, but that would be better than seeing the whole industry gradually collapse under the weight of its own diversity. Second, the industry could begin to address some of the concerns of its critics, by taking more visible measures to ensure competent management and to enhance safety standards. Why not look seriously at alternatives to the much-criticized light-water reactors - at hightemperature gas-cooled reactors or the Swedish PIUS (process inherent ultimately safe) reactors, in which the core and other critical reactor components are submerged in a pool of water? $\square$

\section{How to help Orlov \\ Some of the schemes being considered in the West on behalf of Yuri Orlov will not work.}

SEVEN years ago, the Soviet accelerator physicist, Yuri Orlov, was arrested in Moscow and charged with making anti-Soviet propaganda. At his trial, Orlov was sentenced to seven years in gaol followed by five years of exile. During the first part of his spell in prison, Orlov seems to have been a thorn in the flesh of the prison authorities, protesting at censorship of mail and the molestation of prisoners by their guards. During this period, he seems also to have kept his hand in with his physics. More recently Orlov seems to have been ill, perhaps gravely so. Orlov's case, like Sakharov's, has become to many in the West a test of Soviet attitudes towards professional people who happen to disagree with government policy. Excitement has come to a head (see page 585) now that the more rigorous part of Orlov's sentence is at an end. Will he be released into exile, perhaps abroad, or cynically be kept in gaol?

Orlov was the chief organizer of the group active in Moscow in the mid-1970s in the monitoring within the Soviet Union of the Helsinki agreements. This formless group of undertakings commits its signatories, among other things, to permit the free 